\title{
FINANCIAL SPECULATION IMPACT ON AGRICULTURAL COMMODITY PRICE VOLATILITY: TGARCH APPROACH
}

\author{
Algirdas Justinas Staugaitis ${ }^{1}$, Master in finance science \\ Vytautas Magnus University
}

\begin{abstract}
Motivated by agricultural commodity price fluctuations and spikes in the last decade, we investigate whether financial speculation destabilizes the price of agricultural commodities. The aim of this research is to assess the impact of financial speculation on agricultural commodity price volatility. In our study we use weekly returns on wheat, soybean and corn futures from Chicago Mercantile of Exchange. To measure this impact, we apply autoregressive conditional heteroskedasticity $(\mathrm{ARCH})$ technique. We also propose a model with seasonal dummy variables to measure if financial speculation impact on price volatility differs among seasons. The results of our research indicate that financial speculation as an exogenous factor has either no effect or reduces the volatility of the underlying futures prices. Therefore, we conclude that the increase of non-commercial market participants does not make the agricultural commodity prices more volatile or this link is at least questionable.
\end{abstract}

Keywords: financial speculation, agricultural futures, price volatility, commodity futures markets. JEL code: C58, G13, Q02

\section{Introduction}

Agricultural commodity exchange markets are used to distribute the price risk between agricultural producers and consumers. In the last two decades, major commodity exchange markets became more open to index funds and other investors that do not participate in the underlying agricultural activities. On the one hand, this indicates speculative activity that can potentially affect the prices and cause bubbles. On the other hand, these investors provide the necessary liquidity for these markets to function. The problem whether financial speculation (best described by index funds' net positions) distorts the prices of agricultural commodities have drawn a lot of attention in the recent academic literature. Although many of these studies differ in price measures and other variables used, there is no consensus among authors if financial speculation makes the commodity markets more unstable (Haase et al., 2016). Many authors argue that an increase in non-commercial positions does not disrupt agricultural commodity markets, nor it causes spikes in price levels. Etienne et al. (2017) who used Granger causality tests to analyse Chicago Board of Trade wheat, soybean, and corn markets between 2004 and 2015, provide little evidence that grain futures prices experienced large and prolonged bubbles and that the index investments were causing them. Similar results were achieved by Sanders and Irwin (2010) who used regression models to analyse the relationships between futures returns and long positions of index fund investors in twelve US agricultural commodity markets between 2006 and 2008. On the other hand, these studies lack the emphasis on price volatility and its modelling. A study by Dawson (2015) highlights a high volatility persistence and structural breaks in London International Financial Futures and Options Exchange wheat futures prices between 1996 and 2012. However, it is not clear whether the change in volatility structure is a result of financial speculation. Therefore, the aim of this research is to assess the impact of financial speculation on agricultural commodity price volatility. To achieve this, we first describe the methodology to measure the price volatility and financial speculation, then we analyse the underlying impact of financial speculation on volatility and its clustering.

The complex and non-linear relationships between variables requires advanced techniques in order to achieve more detailed results. Many studies on commodity futures markets use

\footnotetext{
${ }^{1}$ Algirdas Justinas Staugaitis e-mail: ajstaugaitis@gmail.com
} 
autoregressive conditional heteroskedasticity (ARCH) approach (Gupta and Rajib, 2012). According to Silveira et al. (2017) ARCH methods allow to model financial data which do not follow a normal distribution. ARCH methods are primarily used to forecast volatility in futures markets. However, these models can also be used to explain the factors responsible for volatility and its clusters. In our research we apply modified $\mathrm{ARCH}$ techniques to estimate the impact of financial speculation on the volatility of prices. Another important factor within agricultural markets is the seasonality as prices become more volatile prior to harvest times (Karali and Thurman, 2010). Therefore, we also add seasonality to our modelling to see if the effect of financial speculation differs among seasons.

\section{Methodology}

Our research consists of three models: preliminary generalized autoregressive conditional heteroskedasticity (GARCH) model, main threshold generalized autoregressive conditional heteroskedasticity (TGARCH) model and a proposed TGARCH model that uses financial speculation as a multiple seasonal variable. We start our analysis by defining the variables for all three models. First, we generate price return series as the natural log of futures prices:

$$
R_{r}=\ln \left(\frac{P_{t}}{P_{t-1}}\right) * 100 \text {. }
$$

where: $R_{t}$ is price returns on futures, $P_{t}$ is futures price, $t$ is time period, $\ln$ is natural logarithm.

To measure financial speculation in agricultural commodity markets we apply Working $T$ index of excess speculation (Working, 1960). The Working's T index measures the excess of non-commercial positions (index funds positions) relative to commercial positions (agricultural producers' and consumers' positions) and is used in the research on futures markets (Buyuksahin and Robe, 2014). The value of this index cannot be less than 1 . If it is equal to 1 , then all positions in the market are commercial. According to the methodology originally described by Working (1960), we generate a time series of speculative activity index:

$$
T_{t}= \begin{cases}1+\frac{S S_{t}}{H L_{t}+H S_{t}} & \text { if }\left(\mathrm{HS}_{\mathrm{t}} \geq \mathrm{HL}_{\mathrm{t}}\right), \\ 1+\frac{S L_{t}}{H L_{t}+H S_{t}} & \text { if }\left(\mathrm{HL}_{\mathrm{t}}>H S_{t}\right) .\end{cases}
$$

where: $T_{t}$ is working $\mathrm{T}$ index for financial speculation, $S S_{t}$ are non-commercial short positions, $S L_{t}$ are non-commercial long positions, $H S_{t}$ are commercial short positions and $H L_{t}$ are commercial long positions, $t$ is time period.

Next, we perform a test if time series are stationary. In ARCH modeling stationary time series are required in order to obtain consistent parameter estimates (Buyuksahin and Robe, 2014). We perform Augmented Dickey-Fuller test if the data used in our research is stationary - HO: unit root is present; $\mathrm{H} 1$ : alternative hypothesis. Next, we define our preliminary model with 1 time period AR lags $\operatorname{GARCH}(1,1)$. ARCH models consist of two segments: mean and variance equations. We place speculation index in our variance equation:

Mean equation:

$$
R_{t}=\alpha_{0}+\alpha_{1} R_{t-1}+u_{t}
$$

Variance equation:

$$
h_{t}^{2}=\beta_{0}+\beta_{1} u_{t-1}^{2}+\beta_{2} h_{t-1}^{2}+\beta_{3} T_{t-1} .
$$

where: the mean equation consists of returns $R_{t}$ as an autoregressive process with parameters $\alpha_{0}, \alpha_{1}$ and an error term $u_{t}$ with a variance of $h^{2}$. The conditional variance $h_{t}^{2}$ is provided in the variance equation, where $\beta_{0}$ is the constant, $\beta_{1} u_{t-1}^{2}$ is the residual (ARCH) effect, $\beta_{2} h_{t-1}^{2}$ is the variance 
$(\mathrm{GARCH})$ effect. We also use an external variable $\beta_{3} T_{t-1}$ in the variance equation to assess the direct effect of speculation index on conditional volatility.

As an extension to our previously described GARCH model, we use a Threshold Autoregressive Conditional Heteroskedasticity (TGARCH) approach for our main model. In this approach a binary variable is added to estimate the negative return impact on volatility and whether this relationship is asymmetric (Hadsell, 2006). In order to assess the seasonal volatility, time seasons are also added to the variance equation. To avoid multicollinearity, we only use 3 seasons: spring, summer and autumn. Next, we specify our main model based on TGARCH methodology proposed by Zekoian (1994):

Mean equation:

$$
R_{t}=\alpha_{0}+\alpha_{1} R_{t-1}+u_{t}
$$

Variance equation:

$$
h_{t}^{2}=\beta_{0}+\beta_{1} u_{t-1}^{2}+\beta_{2} h_{t-1}^{2}+\beta_{3} T_{t-1}+\beta_{4} u_{t-1}^{2} d_{t-1}+\beta_{5} D P_{t-1}+\beta_{6} D S_{t-1}+\beta_{7} D A_{t-1} .
$$

where: $\beta_{4} u_{t-1}^{2} d_{t-1}$ is the asymmetric component, the parameter $d_{t}=1$ if $u_{t-1}<0$ and $d_{t}=0$ otherwise. If $\beta_{4} \neq 0$, then a threshold effect exists, when $\beta_{4}>0$, the return impact on volatility is asymmetric. $\beta_{5} D P_{t-1}$ is the seasonality parameter to measure the effect of spring, $D P_{t}=1$ if time period $t$ is spring and $D P_{t}=0$ otherwise. $\beta_{6} D S_{t-1}$ is the summer effect. $\beta_{7} D A_{t-1}$ is the autumn effect. Other parameters described in preliminary model (formula 3 and 4).

We also propose an alternative TGARCH model with an additional variable to model financial speculation as a multiple component with seasonal dummy variable. This model allows to assess the season weighted financial speculation and its impact on price volatility. We select spring as the most volatile season for agricultural futures markets. Next, we specify our proposed model:

Mean equation:

$$
R_{t}=\alpha_{0}+\alpha_{1} R_{t-1}+u_{t}
$$

Variance equation:

$$
h_{t}^{2}=\beta_{0}+\beta_{1} u_{t-1}^{2}+\beta_{2} h_{t-1}^{2}+\beta_{3} T_{t-1}+\beta_{4} u_{t-1}^{2} d_{t-1}+\beta_{5} D P_{t-1}+\beta_{6} T_{t-1} D P_{t-1} .
$$

where: $\beta_{6} T_{t-1} D P_{t-1}$ is the multiple effect of speculation index $T_{t-1}$ and season spring effect $D P_{t-1}$. Other parameters described in preliminary and main model (formula 3, 4, 5 and 6).

\section{Data}

In our research we use weekly data for wheat, corn and soybean continuous contracts from Chicago Mercantile of Exchange. The prices for these commodity futures are quoted in US cents per bushel. In our research we cover the time period from January 1986 to July 2019. In total, our analysis covers 1563 weekly observations. We use data on commercial and non-commercial positions to generate the time series of Working $\mathrm{T}$ index of speculative activity (Figure 1 ). 


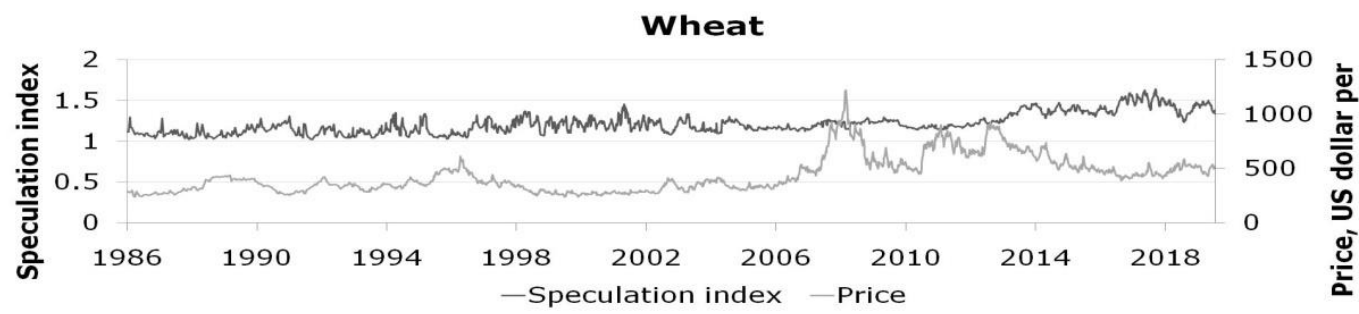

Soybean
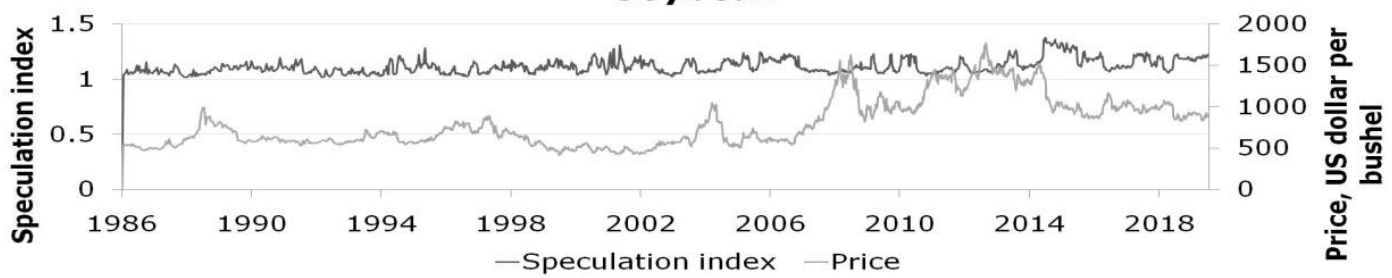

\section{Corn}
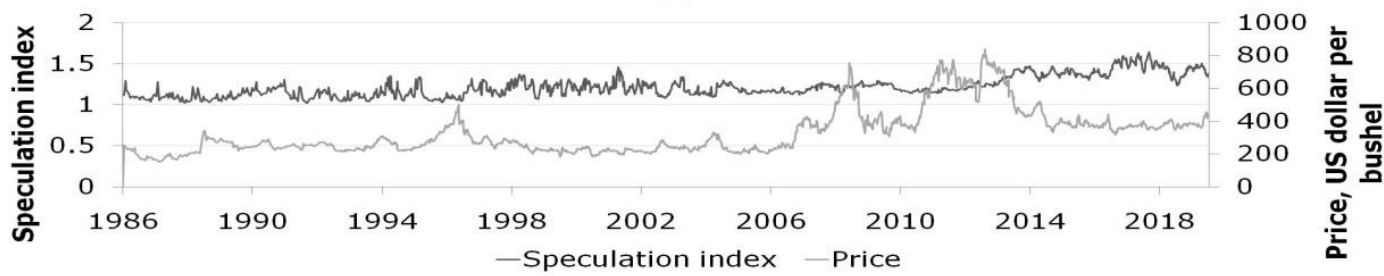

Source: author's calculations based on Chicago Mercantile Exchange data, 2019

Fig. 1. Prices and speculation index for wheat, soybean and corn futures (January 1986-July 2019)

\section{Research results and discussion}

We start our analysis by providing descriptive statistics for wheat, corn and soybean futures from Chicago Mercantile of Exchange (Table 1). We split our time series into two subsamples covering, respectively, 1986-2002 $(n=698)$ and 2003-2019 $(n=865)$. The volatility of returns described by standard deviance is larger in the time period of 2003-2019 for all three agricultural commodities. Jacque-Bera test results meet the significance criteria of q-value $<0.05$ and thus show that sample data have the skewness and kurtosis matching a normal distribution.

Table 1

\section{Descriptive statistics of weekly price returns of agricultural commodity futures}

\begin{tabular}{|c|c|c|c|c|c|c|c|c|c|}
\hline & \multicolumn{3}{|c|}{ Wheat } & \multicolumn{3}{|c|}{ Soybean } & \multicolumn{3}{|c|}{ Corn } \\
\hline & $\begin{array}{c}1986- \\
2019 \\
\end{array}$ & $\begin{array}{c}1986- \\
2002\end{array}$ & $\begin{array}{l}2003- \\
2019\end{array}$ & $\begin{array}{c}1986- \\
2019 \\
\end{array}$ & $\begin{array}{l}1986- \\
2002\end{array}$ & $\begin{array}{c}2003- \\
2019 \\
\end{array}$ & $\begin{array}{c}1986- \\
2019\end{array}$ & $\begin{array}{c}1986- \\
2002\end{array}$ & $\begin{array}{l}2003- \\
2019\end{array}$ \\
\hline Mean & 0.03 & 0.01 & 0.05 & 0.03 & 0.01 & 0.05 & 0.03 & -0.01 & 0.07 \\
\hline Median & -0.07 & -0.06 & -0.10 & 0.14 & 0.09 & 0.21 & 0.00 & 0.00 & 0.05 \\
\hline Minimum & -17.18 & -17.18 & -15.78 & -24.19 & -24.19 & -21.20 & -19.98 & -19.98 & -17.68 \\
\hline Maximum & 18.78 & 18.78 & 16.84 & 13.94 & 13.94 & 11.34 & 21.23 & 20.91 & 21.23 \\
\hline $\begin{array}{l}\text { Std. deviati } \\
\text { on }\end{array}$ & 3.93 & 3.50 & 4.25 & 3.38 & 3.24 & 3.49 & 3.89 & 3.71 & 4.03 \\
\hline Skewness & 0.29 & 0.35 & 0.26 & -0.56 & -0.57 & -0.56 & -0.10 & -0.25 & -0.01 \\
\hline Kurtosis & 1.49 & 2.99 & 0.73 & 3.98 & 6.24 & 2.57 & 4.13 & 6.07 & 2.94 \\
\hline $\begin{array}{l}\text { Jacque- } \\
\text { Bera }\end{array}$ & $167.6 * *$ & $273.3^{* *} *$ & $28.9 * *$ & $1113.0 * *$ & $1169.8^{* *}$ & $282.6 * *$ & $1115.5^{* *}$ & $1077.0 * *$ & $310.9 * *$ \\
\hline
\end{tabular}

Notes: Estimates with $p$-value less than 0.05 are flagged with one asterisk $(*)$, with $p$-value less than 0.01 are flagged with two asterisks (**).

Source: author's calculations based on Chicago Mercantile Exchange data, 2019

Our next step is to test the hypothesis for data stationarity. We provide estimates for ADF statistics for each commodity used in our study (Table 2). Hypothesis $\mathrm{H}_{0}$ of unit root can be rejected for both returns and speculation in all cases, except for speculation index of wheat $(-2.93)$ in 2003- 
2019. The results confirm that further ARCH technique is appropriate for modelling volatility of selected time series.

Table 2

Augmented Dickey Fuller Test

\begin{tabular}{|c|c|c|c|c|c|c|c|c|c|}
\hline & \multicolumn{3}{|c|}{ Wheat } & \multicolumn{3}{|c|}{ Soybean } & \multicolumn{3}{|c|}{ Corn } \\
\hline & $\begin{array}{c}1986- \\
2019\end{array}$ & $\begin{array}{c}1986- \\
2002\end{array}$ & $\begin{array}{l}2003- \\
2019\end{array}$ & $\begin{array}{c}1986- \\
2019\end{array}$ & $\begin{array}{c}1986- \\
2002\end{array}$ & $\begin{array}{l}2003- \\
2019\end{array}$ & $\begin{array}{c}1986- \\
2019\end{array}$ & $\begin{array}{c}1986- \\
2002\end{array}$ & $\begin{array}{l}2003- \\
2019\end{array}$ \\
\hline Price & -2.57 & -2.53 & -2.49 & -2.90 & -3.00 & -2.03 & -2.96 & -2.95 & -2.11 \\
\hline Return & $-40.41 * *$ & $-27.01 * *$ & $-30.04 * *$ & $-40.03 * *$ & $-12.30 * *$ & $-28.87 * *$ & $-18.35^{* *}$ & $-25.59 * *$ & $-15.82 * *$ \\
\hline $\begin{array}{l}\text { Speculation } \\
\text { index }\end{array}$ & $-4.68 * *$ & $-7.18 * *$ & -2.93 & $-8.47 * *$ & $-8.39 * *$ & $-4.76 * *$ & $-7.75^{* *}$ & $-5.81 * *$ & $-5.74 * *$ \\
\hline
\end{tabular}

Notes: Estimates with p-value less than 0.05 are flagged with one asterisk (*), with p-value less than 0.01 are flagged with two asterisks (**).

Source: author's calculations based on Chicago Mercantile Exchange data, 2019

In order to measure the time-varying impact of speculative activity on agricultural futures price volatility, we provide estimates for the preliminary $\operatorname{GARCH}(1,1)$ model (Table 3 ). All three commodities have highly significant volatility (GARCH) effects implying volatility clusters. Residual (ARCH) effect is present in all cases except for whole sample of wheat (0.0744) and corn (0.0632) in 2003-2019. The existence of volatility clustering allows the further modelling of exogenous factors for futures price volatility. However, speculation index is a significant explanatory factor only in case of corn futures $(-0.0214$ with $p$-value less than 0.05 in 1986-2019, -0.0363 with $p$-value less than 0.01 in 2003-2019, Table 3). However, negative estimate of financial speculation indicates that financial speculation has a reverse effect and reduces the price volatility of corn futures.

Table 3

Preliminary GARCH model estimates for agricultural commodity returns

\begin{tabular}{|c|c|c|c|c|c|c|c|c|c|}
\hline & \multicolumn{3}{|c|}{ Wheat } & \multicolumn{3}{|c|}{ Soybean } & \multicolumn{3}{|c|}{ Corn } \\
\hline Period & $\begin{array}{c}1986- \\
2019\end{array}$ & $\begin{array}{c}1986- \\
2002\end{array}$ & $\begin{array}{c}2003- \\
2019\end{array}$ & $\begin{array}{c}1986- \\
2019\end{array}$ & $\begin{array}{c}1986- \\
2002\end{array}$ & $\begin{array}{c}2003- \\
2019\end{array}$ & $\begin{array}{c}1986- \\
2019\end{array}$ & $\begin{array}{c}1986- \\
2002\end{array}$ & $\begin{array}{c}2003- \\
2019\end{array}$ \\
\hline \multicolumn{10}{|c|}{ Mean Equation } \\
\hline constant & -0.0113 & -0.0233 & -0.0107 & 0.0701 & 0.0387 & 0.0955 & 0.0910 & 0.0430 & 0.1699 \\
\hline Return & -0.0163 & -0.0203 & -0.0118 & -0.0338 & -0.0397 & -0.0177 & -0.0269 & -0.0155 & -0.0372 \\
\hline \multicolumn{10}{|c|}{ Variance Equation } \\
\hline constant & 0.0038 & 0.0913 & 0.0390 & 0.0136 & 0.0018 & $0.0251 *$ & $0.0332 * *$ & 0.0297 & $0.0503 * *$ \\
\hline Residual & 0.0744 & $0.1388 * *$ & $0.1148 * *$ & $0.1387 * *$ & $0.1721 * *$ & $0.1089 * *$ & $0.1167 * *$ & $0.1621 * *$ & 0.0632 \\
\hline Volatility & $0.8754 * *$ & $0.4254 * *$ & $0.7826 * *$ & $0.8084 * *$ & $0.7329 * *$ & $0.8418 * *$ & $0.8273 * *$ & $0.7714 * *$ & $0.8877 * *$ \\
\hline $\begin{array}{l}\text { Speculation } \\
\text { index }\end{array}$ & 0.0031 & -0.0331 & -0.0157 & -0.0061 & 0.0079 & -0.0164 & $-0.0214 *$ & -0.0178 & $-0.0363 * *$ \\
\hline
\end{tabular}

Notes: Estimates with p-value less than 0.05 are flagged with one asterisk (*), with p-value less than 0.01 are flagged with two asterisks (**).

Source: author's calculations based on Chicago Mercantile Exchange data, 2019

Next, the asymmetry and seasonality effects are obtained through the estimation of the threshold generalized autoregressive conditional heteroskedasticity (TGARCH) model which is used as the main model for our research. Table 4 results indicate the presence of volatility clusters in both soybean and corn returns as residual and volatility estimates are highly significant similarly to the results of our previous model. The effect of financial speculation on volatility is only present in corn $(-0.0120$ with p-value less than 0.05 in 2003-2019). The further results suggest that there is a strong evidence for an asymmetric effect of volatility shocks of soybean ( -0.6100 with $p$-value less than 0.01 in $2003-$ 2019 ) and wheat (-0.5355 with $p$-value less than 0.01 in 2003-2019). The asymmetry effect in corn futures was only present between 1986 and 2002 (-0.4366 with p-value less than 0.01). However, in all cases the asymmetry estimate is negative, meaning that a positive return increases volatility at a greater extent than a same size negative return. Dummy variables for seasonality indicate that returns on futures prices were significantly more volatile during spring compared to other seasons. 
However, the only exception is soybean futures that were also volatile during summer $(0.0054$ with p-value less than 0.01 in 2003-2019).

Table 4

Main TGARCH model estimates for agricultural commodity returns

\begin{tabular}{|c|c|c|c|c|c|c|c|c|c|}
\hline & \multicolumn{3}{|c|}{ Wheat } & \multicolumn{3}{|c|}{ Soybean } & \multicolumn{3}{|c|}{ Corn } \\
\hline Period & $\begin{array}{c}1986- \\
2019\end{array}$ & $\begin{array}{c}1986- \\
2002\end{array}$ & $\begin{array}{c}2003- \\
2019\end{array}$ & $\begin{array}{c}1986- \\
2019\end{array}$ & $\begin{array}{c}1986- \\
2002\end{array}$ & $\begin{array}{c}2003- \\
2019\end{array}$ & $\begin{array}{c}1986- \\
2019\end{array}$ & $\begin{array}{c}1986- \\
2002\end{array}$ & $\begin{array}{c}2003- \\
2019\end{array}$ \\
\hline \multicolumn{10}{|c|}{ Mean Equation } \\
\hline constant & 0.0038 & -0.0848 & 0.0700 & $0.1560 * *$ & 0.0978 & 0.1935 & $0.1708 * *$ & 0.1332 & $0.2207 * *$ \\
\hline Return & $-0.0280 * *$ & -0.0244 & -0.0242 & -0.0373 & -0.0494 & -0.0094 & $-0.0519 *$ & -0.0141 & $-0.0606 * *$ \\
\hline \multicolumn{10}{|c|}{ Variance Equation } \\
\hline constant & 0.0011 & 0.0055 & 0.0023 & 0.0012 & 0.0027 & 0.0009 & 0.0003 & -0.0004 & 0.0145 \\
\hline Residual & $0.0405 * *$ & 0.0375 & 0.0476 & $0.0489 * *$ & $0.0402 * *$ & $0.0534 * *$ & $0.0430 * *$ & $0.0336 * *$ & $0.0409 * *$ \\
\hline Volatility & 0.9550 & $0.9453 * *$ & $0.9461 * *$ & $0.9511 * *$ & $0.9492 * *$ & $0.9494 * *$ & $0.9594 * *$ & $0.9606 * *$ & $0.9470 * *$ \\
\hline Asymmetry & $-0.3652 *$ & -0.0529 & $-0.5355 * *$ & $-0.5913 * *$ & $-0.6393 * *$ & $-0.6100 * *$ & -0.2438 & $-0.4366 * *$ & 0.0958 \\
\hline $\begin{array}{l}\text { Speculation } \\
\text { index }\end{array}$ & 0.0004 & -0.0030 & 0.0000 & -0.0010 & -0.0017 & -0.0012 & -0.0013 & -0.0004 & $-0.0120 *$ \\
\hline Spring & $0.0048 * *$ & $0.0061 * *$ & $0.0047 * *$ & $0.0033 * *$ & $0.0039 * *$ & $0.0029 *$ & $0.0104 * *$ & $0.0115^{* *}$ & $0.0096 * *$ \\
\hline Summer & -0.0013 & 0.0004 & -0.0021 & $0.0047 * *$ & $0.0045^{*}$ & $0.0054 * *$ & 0.0004 & 0.0004 & 0.0021 \\
\hline Autumn & -0.0022 & -0.0025 & -0.0005 & $-0.0031 * *$ & $-0.0040 * *$ & -0.0019 & -0.0016 & -0.0020 & -0.0008 \\
\hline
\end{tabular}

Notes: Estimates with p-value less than 0.05 are flagged with one asterisk (*), with p-value less than 0.01 are flagged with two asterisks (**).

Source: author's calculations based on Chicago Mercantile Exchange data, 2019

Next, Table 5 shows the results of our proposed modified TGARCH model that includes the product of seasonal dummy variable and financial speculation. An estimate for the ARCH processes indicates similar results as in previous models, the volatility and residual effects are present in all cases except for wheat. The asymmetry between returns and volatility is present and negative in soybean and wheat futures in time period after 2003. The product of financial speculation and seasonal dummy variable has a statistically significant and negative effect on volatility in wheat ( -5.4768 with $p$-value less than 0.01 in 1986-2002) and soybean (-1.9046 with p-value less than 0.01 in 1986-2019, 2.0884 with p-value less than 0.05 in 2003-2019). However, in case of wheat the non-multiple speculation effect was also significant but positive (1.2722 with p-value less than 0.01 in $1986-$ 2002). This can indicate that an increase in non-commercial positions reduces the volatility during more volatile spring season. 
Proposed TGARCH model estimates for agricultural commodity returns

\begin{tabular}{|c|c|c|c|c|c|c|c|c|c|}
\hline \multirow[b]{2}{*}{ Period } & \multicolumn{3}{|c|}{ Wheat } & \multicolumn{3}{|c|}{ Soybean } & \multicolumn{3}{|c|}{ Corn } \\
\hline & 1986-2019 & 1986-2002 & 2003-2019 & $1986-2019$ & 1986-2002 & 2003-2019 & $1986-2019$ & 1986-2002 & 2003-2019 \\
\hline \multicolumn{10}{|c|}{ Mean Equation } \\
\hline constant & -0.0006 & -0.0692 & 0.0499 & $0.1474 * *$ & 0.0812 & 0.1620 & $0.1689 * *$ & 0.1289 & $0.2088 *$ \\
\hline Return & -0.0277 & -0.0280 & -0.0207 & -0.0235 & -0.0375 & 0.0002 & $-0.0500 *$ & -0.0074 & $-0.0606 *$ \\
\hline \multicolumn{10}{|c|}{ Variance Equation } \\
\hline constant & -0.3498 & $-1.2307 *$ & 1.0732 & -0.4197 & -0.4989 & -0.7707 & -0.2379 & -1.0537 & 1.1668 \\
\hline Residual & $0.0390 * *$ & 0.0159 & 0.0622 & $0.0399 * *$ & $0.0402 * *$ & $0.0297 *$ & $0.0421 * *$ & $0.0356 * *$ & $0.0393 * *$ \\
\hline Volatility & $0.9537 * *$ & $0.9496 * *$ & $0.9160 * *$ & $0.9644 * *$ & $0.9556 * *$ & $0.9779 * *$ & $0.9601 * *$ & $0.9571 * *$ & $0.9539 * *$ \\
\hline Asymmetry & $-0.4445^{*}$ & -0.6814 & $-0.4675^{*}$ & $-0.5972 * *$ & $-0.4869 *$ & $-0.9071 *$ & -2.2576 & $-0.4237 *$ & 0.0892 \\
\hline Speculation index & 0.3362 & $1.2722 * *$ & -0.4670 & 0.2838 & 0.3924 & 0.5597 & 0.0520 & 0.8344 & -1.0102 \\
\hline Spring & $2.2654^{*}$ & $7.3280 * *$ & -1.2809 & $2.7780 * *$ & 3.2436 & $2.8739 * *$ & $2.3437 * *$ & $5.4632 * *$ & 0.7818 \\
\hline $\begin{array}{l}\text { Speculation * } \\
\text { Spring }\end{array}$ & -1.2763 & $-5.4768 * *$ & 1.4042 & $-1.9046 * *$ & -0.2121 & $-2.0884 *$ & -1.0347 & -3.7467 & 0.2074 \\
\hline
\end{tabular}

Notes: Estimates with p-value less than 0.05 are flagged with one asterisk (*), with p-value less than 0.01 are flagged with two asterisks (**).

Source: author's calculations based on Chicago Mercantile Exchange data, 2019

In the following, we conclude that realized futures return can be modelled by using ARCH techniques. Time series are stationary, both residual and volatility effects are present in most of cases. Furthermore, we estimate a negative asymmetry effect meaning that an increase in returns is more related to further increase in volatility then vice versa. Our preliminary GARCH model indicates that the presence of financial impact on agricultural futures volatility is only present in corn. However, this impact is negative, meaning that an increase in non-commercial futures positions reduces the underlying price volatility. Similar results are present in our main TGARCH model, only corn futures have a significant but negative effect on volatility. The main model also allows to assess the effect of seasonality on futures price volatility indicating that all agricultural commodities were more volatile during spring, soybean futures were also volatile during summer. In our proposed modified TGARCH model the negative effect of season weighted financial speculation on volatility is mostly present in soybean futures. The effect of financial speculation on wheat is positive and statistically significant, however, the effect is negative for season weighted financial speculation and was only present during time period of 1986-2002. Eventually, we are unable to find the destabilizing effect of financial speculation on underlying futures price volatility. Our study gives the following results: financial speculation as an exogenous factor either had no effect or reduced the volatility or increased the volatility only in time period before 2003. The further investigation on financial speculation impact on price volatility can be expanded by using months instead of seasons, more detailed time periods, also involve more commodity futures.

\section{Conclusions, proposals, recommendations}

1) In our research we analyse the volatility of three agricultural commodities, adopting extended autoregressive conditional heteroskedasticity $(\mathrm{ARCH})$ models. We use realized weekly returns on wheat, soybean and corn futures from Chicago Mercantile of Exchange. The results from analysis show that time series are stationary and include volatility clustering, thus further modelling of exogenous variables using $\mathrm{ARCH}$ techniques is available. In our research we also indicate that futures prices are more volatile during spring as compared to other seasons. 
2) The results of our main and preliminary model analysis show that financial speculation impact on volatility is only present in corn futures. However, this effect is negative, meaning that the increase in non-commercial positions is associated with lower price volatility. In addition, our proposed threshold autoregressive conditional heteroskedasticity (TGARCH) model with financial speculation as multiple factor with seasonality shows that speculation impact on volatility is present in soybean futures but is also negative.

3) The results of our research have important policy implications. Financial speculation is a concern for regulators of futures commodity exchanges to apply a limit on non-commercial positions. Our analysis similarly to other authors indicates that the influence of financial speculation on price level and price volatility in the agricultural markets is at least questionable or in some cases can be opposite as an increase in non-commercial positions can be followed by less volatile prices. However, we also provide evidence that non-commercial positions can make the price more stable or reduce the volatility during the more volatile spring periods.

\section{Refernences}

1. Buyuksahin, B., Robe, M. A. (2014). Speculators, Commodities and Cross-Market Linkages. Journal of International Money and Finance, Volume 42, pp. 38-70.

2. Commitment of Traders, 2019 (2019). Retrieved: https://www.cmegroup.com/toolsinformation/quikstrike/commitment-of-traders.html Access: 30.08.2019.

3. Dawson, P. J. (2015). Measuring the Volatility of Wheat Futures Prices on the LIFFE. Journal of Agricultural Economics, Volume 66, Issue 1, pp. 20-35.

4. Etienne, X. L., Irwin, S. H., Garcia, P. (2017). New Evidence That Index Traders Did Not Drive Bubbles in Grain Futures Markets. Journal of Agricultural and Resource Economics, Volume 42, Issue 1, pp. 45-67.

5. Gupta, S. K., Rajib, P. (2012). Samuelson hypothesis \& Indian commodity derivatives market. Asia-Pacific Financial Markets, Volume 19, Issue 4, pp. 331-352.

6. Haase, M., Zimmermann, Y. S., Zimmermann, H. (2016). The Impact of Speculation on Commodity Futures Markets-A Review of the Findings of 100 Empirical Studies. Journal of Commodity Markets, Volume 3, Issue 1 , pp. 1-15.

7. Hadsell, L. (2006). A TARCH Examination of the Return Volatility-Volume Relationship in Electricity Futures. Applied Financial Economics, Volume 66, Issue 1, pp. 893-901.

8. Karali, B., Thurman, W. N. (2010). Components of Grain Futures Price Volatility. Journal of agricultural and resource economics, Volume 35, Issue 2, pp. 167-182.

9. Silveira, R. L. F., dos Santos Maciel, L., Mattos, F. L., Ballini, R. (2017). Volatility Persistence and Inventory Effect in Grain Futures Markets: Evidence from a Recursive Model. Revista de Administracao, Volume 52, Issue 4, pp. 403-418.

10. Sanders, D. R., Irwin, S. H. (2010). A Speculative Bubble in Commodity Futures Prices? Cross-Sectional Evidence. Agricultural Economics, Volume 41, Issue 1, pp. 25-32.

11. Working, H. (1960). Speculation on Hedging Markets. Food Research Institute Studies, Volume 1, Issue 2, pp. $185-220$.

12. Zakoian, J. M. (1994). Threshold Heteroskedastic Models. Journal of Economic Dynamics and control, Volume 18, Issue 5, pp. 931-955. 